\title{
REDESIGNING THE LEARNING EXPERIENCE: One Professor's EfFor RTS to DeVElop AN ACTIVE AND Engaging First Year Thermodynamics Course
}

\author{
Jillian Seniuk Cicek, Douglas Ruth and Sandra Ingram \\ Faculty of Engineering, University of Manitoba, Winnipeg, MB, Canada R3T 5V6 \\ Corresponding author E-mail address: umseniuk@myumanitoba.ca \\ "become designers of learning experiences, processes, and environments" \\ -James Duderstadt, University of Michigan President [10]
}

\begin{abstract}
Active learning is a pedagogical methodology that research has shown both engages and motivates students. This paper reports on one professor's work to infuse active learning into his first year thermodynamics course. Based on the results of a pilot study aimed at exploring the use of active learning in a first-year thermodynamics course to engage students and improve their learning, a problem-solving learning approach was designed for a subsequent offering of the course. Mini-lectures were interspersed with tutorials, and active learning and pedagogical tools and strategies were employed with the intent to increase student engagement and enhance learning. At the conclusion of this course, a student exit survey and a student focus group were conducted, and students' course marks were compared to their cumulative grade point averages to examine their course performance. Findings showed that students were engaged by the active learning design and evidence of learning was found. This is the second phase of a practical action research study to turn a traditional, lecture-based course into an active learning arena for first year engineering students at the University of Manitoba.
\end{abstract}

Keywords: active learning; student engagement; learning strategies

\section{INTRODUCTION}

Student engagement is a conduit of deep or significant learning [6][10]. It is fundamental in "enhancing students' levels of performance" [4]. Active learning propels student engagement. Courses that are integrated with activities help students practice deep learning and retain the knowledge and skills required for their learning [6]. Active learning also challenges students' cognitive abilities: “...creating effective learning experiences...encourage[ing] students to engage in deep approaches to learning and to integrate their knowledge and skills in solving complex problems" [4].

Active learning methods are learner-centered: they place more of the responsibility for learning on the student [7]. The concept of active learning is found rooted in the work of Dewey, who "equated learning with doing and viewed learning as an activity, a process of discovery, where students need to be actively engaged in all aspects of the learning process" [13]. Instructors adopting active learning strategies are "focusing on the 'ings' (e.g., planning, communicating, designing, problem-solving) rather than just having the class being dominated by the 'ics' (mathematics, physics, dynamics, electronics, etc.)" [13].

Overall, the use of an active, more inductive style of instruction to foster learning instead of more a deductive, traditional type of instruction "is supported by widely accepted educational theories such as cognitive and social constructivism, by brain research, and by empirical studies of teaching and learning" [7]. Using an active, inductive method to facilitate student learning "promotes intellectual development...and help[s] the students acquire the critical thinking and self-directed learning skills that characterize expert scientists and engineers" [7][4]. Therefore, when designing learning experiences for students, it is essential to "remember that what the student does is actually more important in determining what is learned than what the teacher does" [4]. However, what an instructor does to help students actively engage in learning is integral in order to cultivate deep and significant learning in students.

\subsection{Background}

In Winter semester 2013, in the Faculty of Engineering at the University of Manitoba, a doctoral student with a focus on Engineering Education and a Dean Emeritus (the "Professor") conducted a pilot study in cooperation to investigate the use of active learning strategies in a first year engineering course, ENG 1460 
Introduction to Thermal Science (Thermal 1). Based on the data as a result of this pilot study [9], the researchers gained the knowledge that active learning was integral to student engagement and learning. Therefore, it was decided to change the structure of the next offering of Thermal 1 by integrating problem-solving activities (essentially mini-tutorials) with mini-lectures in order to increase student opportunities for active learning, and they student engagement. As well, class tools and strategies were employed as a continuation of what was developed during the pilot study [9] to additionally promote student engagement and learning, and create a supportive learning environment. These tools included the use of course slides, i-clicker exercises, an experimental apparatus, course handouts, a "cheat sheet," stories the instructor told to link course content to the real world, practice problems, and feedback on problems and tests.

The course was offered during the condensed Summer session, which meant that it ran four days a week for six weeks. Thus, three days a week, the Professor combined mini-lectures with problem solving, and one day a week students wrote a test, which the Professor immediately reviewed. The objective of this study was to investigate the effect of the use of active learning strategies on student engagement and learning. Through the use of a student exit survey and a student focus group, as well as the comparison of students' cumulative grade point averages (GPA) with their course grades, the researchers found evidence of student engagement and learning.

\section{METHODS}

A mixed methods approach was designed for this study. Both quantitative and qualitative data were collected and analyzed, and used to triangulate key findings. The quantitative method provides a numerical description of the data, while the qualitative method yields an in-depth view of student experiences, and some understanding of their perspectives and motivations [1][3]. The Professor taught the course using the active learning design, tools and strategies, and the doctoral student solely collected and analyzed all data, so as to guard against potential bias of the results.

\subsection{Respondents}

ENG 1460 Introduction to Thermal Science is a first year engineering course. It is open to all first year university and all engineering students on campus. Sixty-three students were enrolled in the Summer session 2013 offering of the course.

\subsection{Student Exit Survey}

After receiving approval from the Education/Nursing Research Ethics Board (ENREB), which governs all research involving human ethics for the Faculty of Engineering on campus, students were invited to participate in an exit survey during the last week of the course. In the survey, participants were asked about learning styles, and invited to consider the use of tools and strategies to promote engagement and learning in the course. Students were asked to select the best answer or answers in a multiple-choice style questionnaire (see Appendix A). Forty-four out of 63 students completed the exit survey, a $69.8 \%$ response rate. The data from the surveys were analyzed using quantitative descriptive statistics.

\subsection{Student Focus Group Interview}

Once the course was over, and the final grades were calculated and officially entered, students from ENG 1460 Summer session 2013 were sent an email requesting their participation in a focus group interview to further explore their experiences in and perceptions of the course, as well as to discuss the findings of the survey. Two students agreed to participate. The focus group interview was conducted in September 2013, approximately three months after the course was complete. The focus group data were analyzed using the qualitative technique of thorough, deep and recurrent readings to thematically code and report the findings $[1][12][8][2][11]$. Focus group participants were sent both the transcription and analysis of the interview to practice member checking and improve the trustworthiness of the findings [8].

\subsection{Course Grades and Cumulative Grade Point Averages}

Students' course grades and cumulative grade point averages (GPA) were analyzed using a paired t-test with $95 \%$ confidence intervals.

\section{FINDINGS AND DISCUSSION}

There was a large amount of data generated from this study. For the purposes of this paper, only evidence related to student engagement and student learning will be discussed.

\subsection{Evidence of Student Engagement}

The data showed evidence of student engagement in regards to the course design, the use of class tools, the 
student-faculty connection, and the supportive learning environment.

3.1.1 Course Design. The course was structured to integrate problem solving (mini-tutorials) with minilectures: the Professor would conduct a mini-lecture, with a sample problem or two, and then students would work on additional problems while the Professor and teaching assistants circulated throughout the room. When students finished working, the Professor went over the problems with them, and then resumed the mini-lecture-problem solving cycle again. This happened several times a class. While engaged in problem solving, students were encouraged to work with their peers. The data showed that survey participants first preference for learning was through class activities, such as problem solving $(68.2 \%)$. Focus group participants spoke with enthusiasm about the design of the course:

"I really enjoy that part of it... okay have a lecture now, we're going to give you a couple of questions on what we just learned, we're going to do another lecture, I like the way it was broken up..."

They spoke about their interest waning in classes that were predominantly designed around lectures:

"It's just, the interest is going to die out."

“...just listening and taking notes, it gets really tiring."

3.1.2 Class Tools. There was evidence in the data that students were engaged when the course slides, the iclicker exercises, the experimental apparatus, and the cheat sheet were used.

(i) Course Slides. The course slides were designed using animated diagrams and equations, with colorful "Thermodynamic warnings" for students as they were exposed to course content during mini-lectures. Students had access to the slides through the Internet. The data showed that students used the slides both inside (38.6\%) and outside of class $(72.7 \%)$ for preparation and review. The focus group participants found the slides engaging:

"The moving part gets the student actually." [In reference to the animation in the slides.]

"Yeah and then he would say, 'Don't do this!" [In reference to the Professor's "Big Thermodynamic Warning" signs that he would post on the slides.]
"Yeah... like it actually lent like a sense of amusement to it and like, hey I actually want to look in these and have a good laugh over it."

"Yeah, because I usually, I print, I think I printed the first few ones but I just watched the next ones."

(ii) i-clicker Exercises. The Professor used i-clicker exercises to survey students about their understanding and to engage them in their learning. Seventy-one percent of surveyed students found the use of the iclicker exercises "Engaging" or "Very engaging" in the class. The focus group participants also found the exercises engaging, and appreciated their anonymity:

"I think how he did use the i-clickers in the class itself, like okay do you guys understand this, no one would be scared to say I'm scared, I don't understand this cause it's all anonymous right. But so I thought that part was really nice..."

(iii) Experimental Apparatus. An experimental apparatus to model equilibrium was built so that the Professor could demonstrate the concept to the class.

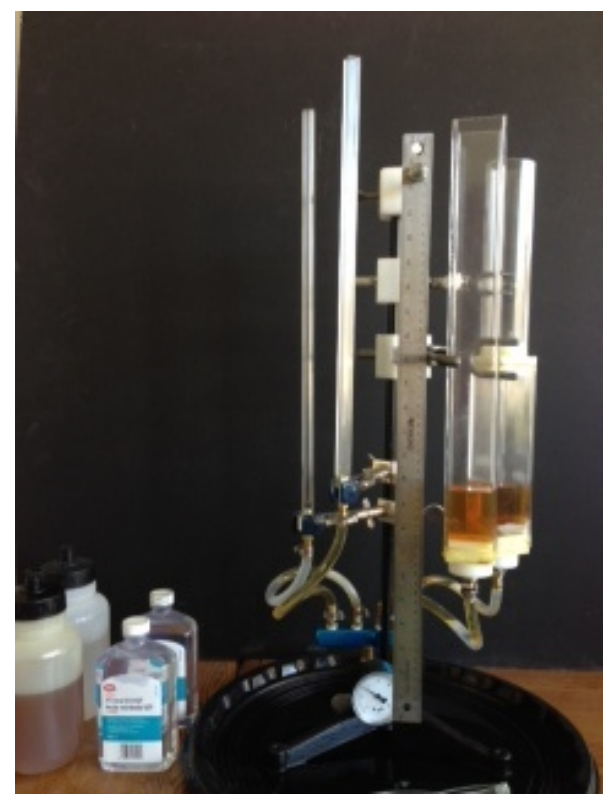

Fig. 1: Experimental apparatus to model equilibrium.

When asked about this apparatus, the focus group participants were very enthusiastic about it:

"I thought that was cool, it was cool to see it actually being in use... And you can actually see, oh this makes sense, I understand this, you can actually physically see it go..." 
"Especially for first years, cause they want to see that. The higher years they know... they've seen it before and the first year would be interested, oh this is what I, I would do or I would understand in the future..."

When surveyed, $71.7 \%$ of participants found the use of the experimental apparatus to model equilibrium in class "Engaging" or "Very engaging."

(iv) Cheat Sheet. Students were allowed to bring one sheet of paper with them into the tests and exams. The Professor modeled how to create this "cheat sheet" by demonstrating which formulas he would write down. The focus group participants showed their enthusiasm when they discussed this class tool:

"I have that with me every time...the girl that I was talking to [you about] before, she was confused on this one question... and I was showing this to her, and she's like whoa, wow, that's a lot... so it's nice and I can have all those little points to it and I wrote that down, I've written that on every single one since we got that, it's a nice way to be able to see and that also I feel stops the panic.

3.1.3 Student-Faculty Connections: Stories. Studentfaculty contact is one of the principles of good practices in higher education according to Chickering and Gameson [10]. Research has shown that student interactions with faculty and peers have the largest positive effect on the general education of students [10][7]. The Professor told stories in class in order to connect to students, and to illustrate how course content related to the real world in order to create an authentic learning environment [5] to engage students. When survey participants were asked their preferred style of learning, the least selected category was "stories that the instructor tells that relate to the class" (34.1\%). However, in the course observations that the doctoral student conducted, students showed engagement during the Professor's anecdotes through their eye contact, smiles and laughter. Both focus group participants thought that stories did help connect students to the real world, which was the intention of using the anecdotes, and which they appreciated:

"I definitely think that they did help connect it, you could actually see... examples... it was kind of nice, oh okay, so it was a real person... they're doing something that we're still using today."

However, the focus group discussion of this strategy was not as animated as participants' discussions of other strategies. Evidently, as seen through the survey and the focus group, students preferred the active teaching strategies to the passive strategies that were used.

3.1.4 Supportive Learning Environment. One factor that increases students' engagement in learning is "students' perception of how well the learning environment set by the instructor supports their learning" [4]. Students were surveyed to determine if they were aware of the professor's concern for their learning. Ninety-one percent of students felt that the Professor was concerned "Quite a bit" or "Absolutely, a lot" with their learning. This was reflected in the focus group interview. Both focus group participants spoke without prompting about the impact the Professor had on their learning. This included the Professor's willingness to help his students; how he was always "there" or present when he was teaching; and that he was human, sharing his own struggles and failures during first year university, which demonstrated to the focus group participants that they could be successful too:

"...the way he was able to explain things, you just got them and if you didn't he was really open about helping..."

"You remember it that much better and just the way he taught the class... when he was doing the lectures themselves he was there and he was really alive for them..."

"If you want to be able to see, if you can't study, if you don't know how to study and I remember [him] saying that he didn't do well his first year in university...

"Yeah, he said that."

"Yeah."

"Yeah, it makes him more human in front of..."

"Exactly. And he reached, he became a doctor, he became a dean."

\subsection{Evidence of Student Learning}

Evidence of student learning was seen through the in-class activities, the practice problems, course handouts, cheat sheet, and feedback provided throughout the course. Learning was also evidenced through the comparison of the course marks with students' cumulative grade point average (GPA).

3.2.1 In-Class Activities. Seventy percent of surveyed participants felt that in-class activities, including problem solving, helped them learn better. Both focus group participants spoke about how in order to learn effectively and retain knowledge, they needed to be able to do the activity, i.e., solve the problem in class. This 
strengthened their learning, and prepared them for subsequent engineering courses:

"...the way that the course was set up it facilitated that and made that a lot easier to recall what you learnt."

“...if you're doing it, I think we will remember it more..."

“...You can't just get by on listening to the Professor... You need to go out and try and do the questions."

"I think every course, every course in engineering especially is, isn't a bystander sport, like a phrase that they used, you can't get through...you won't get through your second year, you're going to fail everything. And it's because if you don't have the practice on how to do the questions and to do them quick you won't be able to finish and you won't be able to keep up..."

3.2.2 Practice Problems. Each week, the Professor routinely reviewed old exams with the students and assigned voluntary practice problems to support their learning. The majority of students responded that they did the practice problems at least some of the time $(90.9 \%)$ and felt that the practice problems increased their learning of the course material "Quite a bit" to "A lot" $(75.6 \%)$. Both focus group participants also espoused this practice. They emphasized the importance of solving the practice problems to succeed in the course and increase their learning:

"That's because of all the practice that I had... the way that [he] taught the course and the way that we've been doing it and him especially going through old exams with us I found helped so much."

"So having us do the questions during class, he made sure that we were having the practice...he knew we had that practice."

"...if you practice actually you get higher marks, so you have to do it."

3.2.3 Course Handouts and the Cheat Sheet. The Professor constructed two handouts for the students as a result of the findings generated in the pilot study. One was a flow device/control-volume equations handout for turbines, compressors, and other energy transfer systems, and the other was the handout to identify properties and states. The focus group participants were very positive about both handouts, as well as the cheat sheet, and spoke about how they were so effective in reinforcing their learning and helping them plan their learning that eventually they did not need them to do the work anymore:

"Sweet, okay awesome... one was for the state points and figuring out if you knew what the state was... so like mass and two properties and then the other was what type of system and the different ways that you could use it, totally helpful..."

"...the best way for me to study was to actually completely ignore what I wrote in my notes, look at the cheat sheet or the formula sheet that we made for the term tests and use it ..."

"He gave it to us and then when he discusses a problem he would ask us what... state, do you have this, do you have that... And then you don't need the cheat sheet anymore because you remember it."

3.2.4 Feedback. After the second week of class, the Professor administered a weekly test. When all of the students had finished writing it, the Professor immediately went over the questions with any students who wished to stay and get the feedback. All of the survey participants found this at least somewhat helpful for their learning, with $76.2 \%$ of participants finding it "Quite a bit" to "Absolutely, a lot" helpful. Focus group participants added that it relieved their anxiety about their performance on the test, and freed up their minds so they could focus on the next task at hand.

"But actually that also helps the students, you don't have that days of thinking what would I get... What will I get and screwing [up] other stuff."

Feedback was also provided during each class, from the Professor, the teaching assistants (TAs) and students' peers. The professor and the TAs also circulated around the room when students were problem solving in groups, and the Professor went over the assigned problems once students had solved them. This afforded students instant feedback from a number of sources during the class, which supported students' learning. Both focus group participants spoke about this at length:

"...he was always there, he was always 'okay guys do you guys understand this, do you guys get this?', always really quick."

"...you could ask anyone in the class about it, you could ask the TAs, you constantly had people 
there that you were able to ask and at different times."

"And if you talked with people while doing the problem that's actually, I think you know that already, that you'll learn more, if you tell someone what to do and they tell you what to do as well."

"Exactly, and you're not thinking right at the surface stuff...Y You're actually trying to scratch and, and figure out why I don't get it."

\subsubsection{Course Grades Compared to Grade Point} Averages. When students' course marks were compared to their cumulative grade point averages (GPA) to examine students' performance in the course, it was found that $86.2 \%$ of the students had higher course marks than GPAs (see Fig. 1). A paired t-test with 95\% confidence intervals was conducted. The results showed that there is a difference between course marks and cumulative GPA (paired t-test, $p$ value of $<0.0001$ ). These results cannot be unquestionably linked to the active learning design in this course as a number of other factors were not accounted for, such as the course being held during Summer session when a lighter course load or the duration or intensity of the course could affect student achievement. However, it is a source of data worth further investigation as this research study is continued.

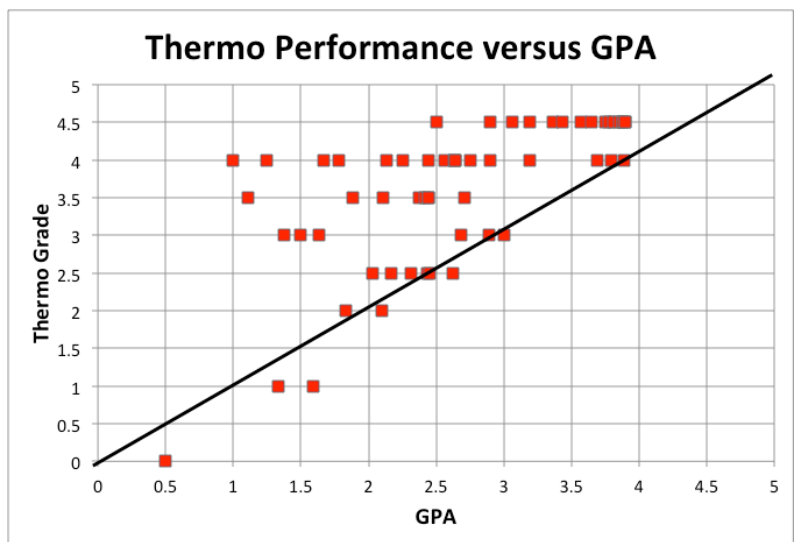

Fig. 2. Comparison of course grade to cumulative grade point average (GPA).

\section{CONCLUSIONS}

This study explores the impact of one Professor's use of active learning strategies in his first year Thermodynamics course through students' experiences and perceptions, as well as their course grades compared to their cumulative grade point averages. The course was designed based on the findings from a pilot study conducted in Winter 2013. To strengthen this study, both quantitative and qualitative methodologies were harnessed, and data was gathered using a student exit survey and a student focus group interview.

The exit survey had a high response rate. Unfortunately, there were only two focus group participants. This was most likely due to the fact that the end of the course coincided with the start of summer vacation. Self-selection could be a factor in the kind of findings that were obtained from the focus group data. However, it is noteworthy that both of the participants were able to elucidate a detailed account of their engagement and learning even three months after the course had concluded. Additionally, focus group data were triangulated with exit survey data to strengthen the findings.

Data showed that students were engaged through several means: by the active learning design of the course, the use of active learning and other pedagogical tools and strategies, including course slides, i-clicker exercises, the experimental apparatus, the cheat sheet, the Professor's stories, and the supportive learning environment. Student learning was reinforced by the class activities, practice problems, course handouts and cheat sheet, and feedback provided by the Professor, teaching assistants and students' peers. Learning was also evidenced when students' course marks were compared with students' cumulative grade point averages (GPA), although this cannot be unequivocally attributed to the active learning design.

The researchers of this study will continue to explore the impact of active learning on student engagement and learning in the next offering of Thermal 1, planned for Summer session 2014. In the interim, with the knowledge that the design of mini-lectures infused with problem-solving activities is an effective way to support student learning in a first year thermodynamics course, there are plans underway to implement this design in all subsequent offerings of this course in the faculty.

\section{Acknowledgements}

This research study was funded by the NSERC Chair in Design Engineering program at the University of Manitoba; Dr. Ingram's University of Manitoba Faculty of Engineering Start-up Grant; and Jillian Seniuk Cicek's University of Manitoba Graduate Fellowship (UMGF) and Manitoba Graduate Scholarship (MGS). The authors of this paper would also like to thank Warren Blunt for his help with the statistical analysis. 


\section{References}

[1] John W. Creswell, Qualitative Inquiry and Research Design: Choosing Among Five Approaches. Thousand Oaks, CA: Sage Publications, 2007, (2nd ed.), 395 pp.

[2] Marcia Friesen, K. Lynn Taylor and M.G. (Ron) Britton, "A qualitative study of a course trilogy in biosystems engineering design," Journal of Engineering Education, vol. 94, no. 3, pp. 288-296, 2005.

[3] Jon A. Leyden, Barbara M. Moskal and Michael J. Pavelich, "Qualitative methods used in the assessment of engineering education," Journal of Engineering Education, vol. 93, no. 1, pp. 65-72, 2004.

[4] Thomas A. Litzinger, Lisa R. Lattuca, Roger G. Hadgraft and Wendy C. Newstetter, "Engineering education and the development of expertise," Journal of Engineering Education, vol. 100, no. 1, pp. 123-150, 2011.

[5] Ellin Oliver Keene and Susan Zimmermann, Mosaic of Thought: The Power of Comprehension Strategy Instruction. Portsmouth, NH: Heinemann, 2007 (2nd ed.), 312 pp.

[6] Michael J. Prince, "Does active learning work? A review of the research," Journal of Engineering Education, vol. 93, no 3, pp. 223-231, 2004.

[7] Michael J. Prince and Richard M. Felder, "Inductive teaching and learning methods: Definitions, comparisons, and research bases," Journal of Engineering Education, vol. 95, no. 2, pp. 123-138, 2006.

[8] Johnny Saldana, The Coding Manual for Qualitative Researchers. Thousand Oaks, CA: SAGE, 2009, 223 pp.

[9] Jillian Seniuk Cicek, Douglas Ruth and Sandra Ingram, ““"Thermodynamics is not a spectator sport!": An exploratory study on incorporating active learning into a first year thermodynamics course" in Proc. CEEA Canadian Engineering Education Conf., CEEC13, Michel Perrier and Sylvan Turenne (eds.) (Montreal, QC; 18-20 June 2013), 8 pp., 2013.

[10] Karl A. Smith, Sheri D. Sheppard, David W. Johnson and Roger T. Johnson, "Pedagogies of engagement: Classroombased practices," Journal of Engineering Education, vol. 94, no. 1, pp. $87-101,2005$.

[11] Karen L. Tonso, "The impact of cultural norms on women," Journal of Engineering Education, vol. 100, no. 3, pp. 217-225, 2011.

[12] Joseph S. Wholey, Harry P. Hatry and Kathryn E. Newcomer (eds.), Handbook of Practical Program Evaluation. San Francisco, CA: Jossey-Bass, 2010 (3rd ed.), 710 pp.

[13] Aman Yadav, Dipendra Subedi, Mary A. Lundeberg and Charles F. Bunting, "Problem-based learning: Influence on students' learning in an electrical engineering course," Journal of Engineering Education, vol. 100, no. 2, pp. 253-280, 2011.

\section{APPENDIX A: SAMPLE OF STUDENT EXIT SURVEY}

This is a survey designed to gather your feedback now that you have taken ENG1460 - Introduction to Thermal Science Intercession 2013. Please circle the letter or letters of your choice or choices.

Why did you choose this section of ENG 1460 (Intersession: May/June)?
A. Fit in my schedule.
B. Like the length of Intersession.
C. Like the concentrated learning of Intersession.
D. Couldn't get into another section.

The places I used the slides included:
A. Outside of class for preparation.
B. Outside of class for review.
C. In tutorials.
D. During class.

Had you used i-Clickers before this course?
A. In one course.
B. In two courses.
C. In three courses.
D. In more than three courses.

How did you find the i-Clickers in class:
A. Not interesting.
B. Somewhat interesting.
C. Engaging.
D. Very engaging
E. No opinion.

If you used the i-Clickers in class did you find them helpful:
A. No, unhelpful.
B. Can't tell/unsure.
C. Yes, helpful.
D. Yes, very helpful.

Did it help your learning to go over the test immediately after it was written?
A. Not at all.
B. Somewhat.
C. Quite a bit.
D. Absolutely, a lot.
Did you do the practice problems?
A. I did not do them.
B. I did them sometimes.
C. I did them quite a lot.
D. Absolutely, I did them all.
E. I wasn't aware of them.

If you did the practice problems, did they increase your learning of the course material?
A. Not at all.
B. Somewhat
C. Quite a bit.
D. Absolutely, a lot. 